\title{
A PESQUISA DE CAMPO NA FORMAÇÃO DOCENTE EM GEOGRAFIA: EXPERIÊNCIA DE UM “OLHAR ENCARNADO” NO TERRITÓRIO DO CERRADO
}

\author{
Ana Carolina de Oliveira Marques ${ }^{1}$ \\ Genildo Francisco da Costa ${ }^{2}$
}

Resumo: Este artigo trata do papel da pesquisa de campo na formação docente em Geografia, compartilhando a experiência educativa realizada com acadêmicos da Universidade Estadual de Goiás. O trabalho de campo realizado no préassentamento rural Paulo Gomes (Itapuranga/ Goiás) incitou um estudante a representar, por meio de desenhos, a memória camponesa dos mutirões. Ao compor os desenhos, o futuro professor se deparou com valores e saberes de sujeitos concretos, valores estes que circulam na sala de aula e demandam reconhecimento. Geografia e arte se fundiram no "olhar encarnado" (MARANDOLA JR., 2018) de Genildo Francisco da Costa que, ao representar os territórios camponeses do Cerrado, recorreu às memórias de sua infância num processo gradativo da tomada de consciência de si.

Palavras-chave: Ensino de Geografia; Pesquisa; Valores Camponeses; Mutirão.

\section{FIELD RESEARCH IN TEACHER TRAINING IN GEOGRAPHY: EXPERIENCE OF "INCARNATED LOOK" IN THE CERRADO TERRITORY}

\begin{abstract}
This article deals with the role of research in teacher training in Geography, sharing the educational experience conducted with academics from the State University of Goiás. The fieldwork carried out in the pre-settlement Paulo Gomes (Itapuranga/Goiás), encouraged a student to represent, through drawings, the peasant memory of the "mutirões". When composing the drawings, the future teacher came across the values and knowledge of concrete subjects, values that circulate in the classroom and demand recognition. Geography and art merged in the "incarnated look" (MARANDOLA JR., 2018) of Genildo Costa that, in representing the peasant territories of the Cerrado, resorted to your childhood memories in a gradual process of self-awareness.
\end{abstract}

Keywords: Geography Teaching; Research; Peasant Values; Mutirão.

\footnotetext{
${ }^{1}$ Doutora em Geografia. Docente na Universidade Estadual de Goiás (UEG) carol.geografia@ hotmail.com.

${ }^{2}$ Licenciado em Geografia. genildofcosta@ hotmail.com.

Estudos Geográficos, Rio Claro, 17: 205-215, jan./jun. $2019 \quad$ (ISSN 1678-698X) http://www.periodicos.rc.biblioteca.unesp.br/index.php/estgeo
} 
A pesquisa de campo na formação docente...

\section{INTRODUÇÃO}

Muito se fala sobre a fragilidade da pesquisa no habitus do professor de Geografia da Educação Básica. Por outro lado, critica-se o desprezo às questões pedagógicas nas pesquisas desenvolvidas nos grandes centros universitários. Tratase, ao final, da qualidade da relação entre Ensino e Pesquisa, Escola e Universidade.

Este texto é um convite para se pensar o papel da pesquisa, sobretudo da pesquisa de campo, na formação docente em Geografia. A pesquisa entendida como componente fundamental do processo educacional, afinal é por meio dela que novos conhecimentos podem ser produzidos, rompendo com uma lógica há muito denunciada de um ensino repetitivo e alheio às particularidades dos sujeitos e lugares.

A pesquisa de campo, enquanto prática pedagógica no ensino de geografia, aparece aqui não como exercício de comprovação do conteúdo ensinado em sala de aula. É, acima de tudo, oportunidade de produzir novos sentidos a partir da interação dos professores e estudantes com outros saberes, outras linguagens, outros territórios, outras cosmologias humanas. Também um convite à dilatação das habilidades de observar, descrever, narrar, coletar dados e informações do real, sentir e se emocionar.

No campo, o raciocínio geográfico e a consciência espacial são postos à prova: a leitura das paisagens, a capacidade de diálogo com os sujeitos do lugar, a excitação dos sentidos humanos, a operacionalização dos conceitos geográficos, o raciocínio escalar.

Tais premissas fundamentaram a experiência educativa da pesquisa de campo realizada com acadêmicos da Universidade Estadual no Pré-Assentamento Paulo Gomes (Itapuranga/Goiás). O campo incitou um estudante a representar, por meio de desenhos, a memória camponesa dos mutirões. Ao compor os desenhos, o futuro professor se deparou com valores e saberes de sujeitos concretos, valores estes que circulam na sala de aula e demandam reconhecimento.

Este texto está estruturado em três tópicos. Inicialmente, provoca-se o leitor para questões gerais pertinentes à formação do professor-pesquisador. Em seguida, debruça-se sobre o papel da pesquisa de campo na formação docente em Geografia. Por fim, compartilha-se a experiência mencionada há pouco com a exposição de fotografias e desenhos de autoria de Genildo Francisco da Costa.

\section{A FORMAÇÃO DO PROFESSOR-PESQUISADOR}

A compreensão equivoca da distinção entre a Geografia Acadêmica e a Geografia Escolar compromete a prática da pesquisa na Educação Básica. Enquanto a primeira é concebida como centro de produção do conhecimento, a Geografia Escolar é atrelada a uma lógica de reprodução do conhecimento sistematizado de forma simplificada.

No imaginário social, a Geografia aparece como o estudo dos lugares, ou seja, campo disciplinar que "apresenta" o mundo através de uma exaustiva descrição de paisagens e lugares já conhecidos e descritos. Daí, decorre um ensino mnemônico e enciclopédico (GIROTTO, 2015). Esse raciocínio conduz ainda ao questionamento da importância da Geografia Escolar diante da difusão das tecnologias de informação e comunicação na era digital: o acesso ampliado às

Estudos Geográficos, Rio Claro, 17(1): 205-215, jan./jun. 2019 (ISSN 1678-698X) http://www.periodicos.rc.biblioteca.unesp.br/index.php/estgeo 
informações sobre os lugares torna o ensino de Geografia obsoleto? Qual é mesmo a finalidade desta disciplina?

Para Kozel e Filizola (1996) a finalidade da educação geográfica é o desenvolvimento do raciocínio geográfico e da consciência espacial, o que remete à internalização de conceitos geográficos e ao raciocínio escalar. Para Douglas Santos (2007), o objetivo do ensino de Geografia é instrumentalizar o educando na resposta da questão "onde estou?". Lembrando que não bastam as informações topográficas, é preciso desvendar a ordem topológica das coisas, ou seja, o por quê de suas localizações.

Uma síntese de tais pensamentos sugere a Geografia como campo disciplinar que forma o educando para ler e interpretar o espaço de diferentes perspectivas ou escalas de análise, de forma a desenvolver habilidades de raciocínio que lhes permita situar-se nos espaços de relação. $O$ acesso à informação não basta, pois é o raciocínio geográfico que possibilita o deslocamento do pensamento em diferentes escalas e o ajuste constante entre teoria (conceitos geográficos) e prática (vida cotidiana), condição para a interpretação do espaço geográfico.

Assim como não bastam as informações disponíveis nas plataformas digitais, são insuficientes os currículos oficiais (ARROYO, 2014). Teóricos da educação alertam para a necessidade de situar os conteúdos escolares tomando os contextos socioeconômicos e culturais como ponto de partida, a exemplo de Freitas (1994) e Freire (1987). Como, então, realizar um ensino de Geografia situado espacial e culturalmente, voltado ao desenvolvimento do raciocínio geográfico/escalar pelo educando?

Primeiro, há que "dessacralizar" a forma e o conteúdo do ensino de Geografia. Ambos são passíveis de críticas e reformulações. Isto implica uma atitude filosófica por parte do professor. Trata-se de questionar as bases políticas e pedagógicas da educação, entendendo-as como produto histórico e social. Assim, o professor se reconhecerá sujeito ativo do processo educacional e não peça de uma engrenagem estática e imutável.

Ver-se como pesquisador, ou seja, partícipe do processo de produção de novos conhecimentos é condição para que o professor situe sua prática no contexto em que atua. Os problemas ambientais e territoriais que afligem a comunidade local, o perfil socioeconômico e subjetivo dos educandos, as demandas do mercado de trabalho, as novas metodologias de ensino, a conjuntura político-econômica, as mudanças na legislação educacional são alguns dos temas que influenciam diretamente a prática docente, desdobrando-se em problemas de pesquisa.

Manuais de metodologia científica indicam diversas tipologias de pesquisa: exploratória, documental, bibliográfica, aplicada, etnográfica, pesquisa-ação, estudo de caso etc. No âmbito da Geografia, a pesquisa ou trabalho de campo - e a cartografia - definem o "espírito geográfico" (AMORIM FILHO, 2015). É ela o objeto de discussão do próximo tópico.

Estudos Geográficos, Rio Claro, 17(1): 205-215, jan./jun. 2019 (ISSN 1678-698X) http://www.periodicos.rc.biblioteca.unesp.br/index.php/estgeo 


\title{
O TRABALHO DE CAMPO NA FORMAÇÃO DOCENTE
}

\author{
"Vemos o campo pelo olhar do método. O \\ método é a expressão de nossa \\ concepção de mundo".
}

(Dirce Suertegaray, 2002)

As fragilidades do trabalho de campo enquanto recurso pedagógico na educação geográfica remetem não só às condições precárias do trabalho docente no ensino básico, mas a lacunas nos cursos de formação de professores. Yves Lacoste (2005), em 1977, alertou para a tendência da "Geografia dos Professores" em reproduzir o conhecimento sistematizado em detrimento da produção de novos conhecimentos. Compreendido desta forma, o trabalho de campo se torna prática dispensável para alguns geógrafos, da universidade à escola.

A dispensa do campo por parte dos professores de Geografia fragiliza o elo entre teoria e prática. A Geografia Escolar ao enclausurar-se na sala de aula, distancia-se não só física, mas político e epistemologicamente dos problemas da sociedade concreta, origem e finalidade do saber geográfico.

Defende-se a tese de que o trabalho de campo é condição de um "olhar encarnado" (MARANDOLA JR, 2018), matriz de um ensino criativo atrelado à práxis. Nesse sentido, dois aspectos serão desenvolvidos ao longo deste tópico: 1. A natureza do trabalho de campo conforme as orientações teórico-metodológicas; 2 . 0 olhar encarnado como exercício de consciência de si e do mundo.

A geógrafa Dirce Suertegaray publicou um texto, em 2002, intitulado "Pesquisa de Campo em Geografia". A publicação versa sobre variados métodos adotados por geógrafos e suas implicações na pesquisa de campo, lembrando que o campo não é exclusividade da Geografia. Antes de transpor algumas reflexões da autora, cabe aproximar as noções de "trabalho de campo" de "pesquisa de campo".

Segundo Lacoste (2005), o fundamento do trabalho de campo - no âmbito do ensino de Geografia - é a pesquisa. Para o geógrafo crítico, a função do campo não seria a mera comprovação do conteúdo trabalhado em sala de aula, mas a produção de novos conhecimentos em conformidade aos sujeitos e lugares situados espaço e temporalmente. Trabalho e pesquisa de campo se fundem, portanto, na visão de Yves Lacoste.

Retornando a Suertegaray (2002), as práticas de pesquisa de campo na Geografia podem ser agrupadas segundo três orientações metodológicas: positivista, dialética e hermenêutica-fenomenológica. Em cada uma delas, a relação sujeito-objeto ganha contornos próprios.

A perspectiva positivista remete à filosofia grega, em especial ao conceito aristotélico de verdade, resgatado por Comte. A verdade, no positivismo, localiza-se no objeto, sendo este externo e independente do sujeito. Cabe ao pesquisador, por meio da observação e descrição objetiva, captar a verdade, ou seja, as leis naturais e imutáveis de funcionamento do objeto. As técnicas e a caracterização (matemática) dos fenômenos ganham centralidade nesta concepção, fundada sobre o princípio da neutralidade científica. Aqui, o campo pode ser inclusive substituído por operações via softwares de processamento e representação cartográfica de dados.

Estudos Geográficos, Rio Claro, 17(1): 205-215, jan./jun. 2019 (ISSN 1678-698X) http://www.periodicos.rc.biblioteca.unesp.br/index.php/estgeo 
Em oposição ao positivismo e neopositivismo, na dialética sujeito e objeto se relacionam. O objeto é a extensão do sujeito. Conhecer o objeto é conhecer e transformar a si mesmo. Pensar e transformar se fundem na mesma operação: surge a "práxis". O engajamento do sujeito no objeto é a condição para uma nova consciência de mundo. O compromisso social é, dessa forma, pressuposto político do trabalho de campo de orientação marxista.

Na perspectiva hermenêutica-fenomenológica, dilui-se ainda mais a fronteira entre sujeito e objeto. $O$ sujeito se constitui no e pelo objeto. $O$ campo é texto, documento de formas de vida, do movimento do sujeito no mundo. Experiência, ação, vivência, corpo, geograficidade, prática espacial, desejo, emoção, afeto, sensibilidade compõem o geográfico. Esta é a perspectiva da qual emana a proposta de um olhar encarnado.

Filiado à Geografia Humanista, o olhar encarnado lança luz aos atravessamentos - cor, etnia, sexualidade, religiosidade, classe, gênero etc. - que incidem sobre os sujeitos de carne e osso. Marandola Jr. (2018) situa esta proposta entre a fenomenologia e a decolonialidade. Contrapõe-se a uma abordagem numérica/abstrata de população, reclamando as experiências corpóreas integrais dos sujeitos, não só os sentidos distais (audição e visão).

A Geografia Encarnada sugere uma outra formação ao professor de Geografia, atenta à dimensão humana dos lugares e do próprio trabalho de campo enquanto prática de consciência de si e do mundo. Há, porém, cuidados a serem tomados, como o superdimensionamento do campo em detrimento da teoria. Nesse sentido, Lacoste (2005) é contundente ao dizer que o campo é "prática indispensável, mas insuficiente", sob o risco de empirismo.

\section{A EXPERIÊNCIA EDUCATIVA NO PRÉ-ASSENTAMENTO PAULO GOMES}

O trabalho iniciou nas aulas da disciplina "Didática e Prática Docente em Geografia. Após a leitura e discussão de alguns dos textos referenciados nos tópicos anteriores, em março de 2018, acadêmicos do $5^{\circ}$ período da licenciatura plena em Geografia da Universidade Estadual de Goiás/Campus Itapuranga realizaram o trabalho de campo no Pré-Assentamento Paulo Gomes.

Nesse espaço em formação há cerca de 2 anos vivem 12 famílias que aguardam a regularização do terreno. Abrigadas em barracas de lona, os assentados e assentadas carecem de serviços básicos de energia elétrica, água encanada, saneamento básico, transporte público.

Há um ano e meio a UEG é parceira do PA Paulo Gomes por meio da Incubadora Tecnológica de Cooperativas Populares e Empreendimentos Solidários (ProSol), do qual fazem parte mulheres - agricultoras, artesãs, doceiras - do préassentamento.

Fomos recebidos com uma mística que envolvia canções da luta pela terra, instalações de artesanatos, objetos-símbolo do movimento social, frutos do Cerrado, produtos agrícolas in natura e processados no interior do pré-assentamento.

Estudos Geográficos, Rio Claro, 17(1): 205-215, jan./jun. $2019 \quad$ (ISSN 1678-698X) http://www.periodicos.rc.biblioteca.unesp.br/index.php/estgeo 


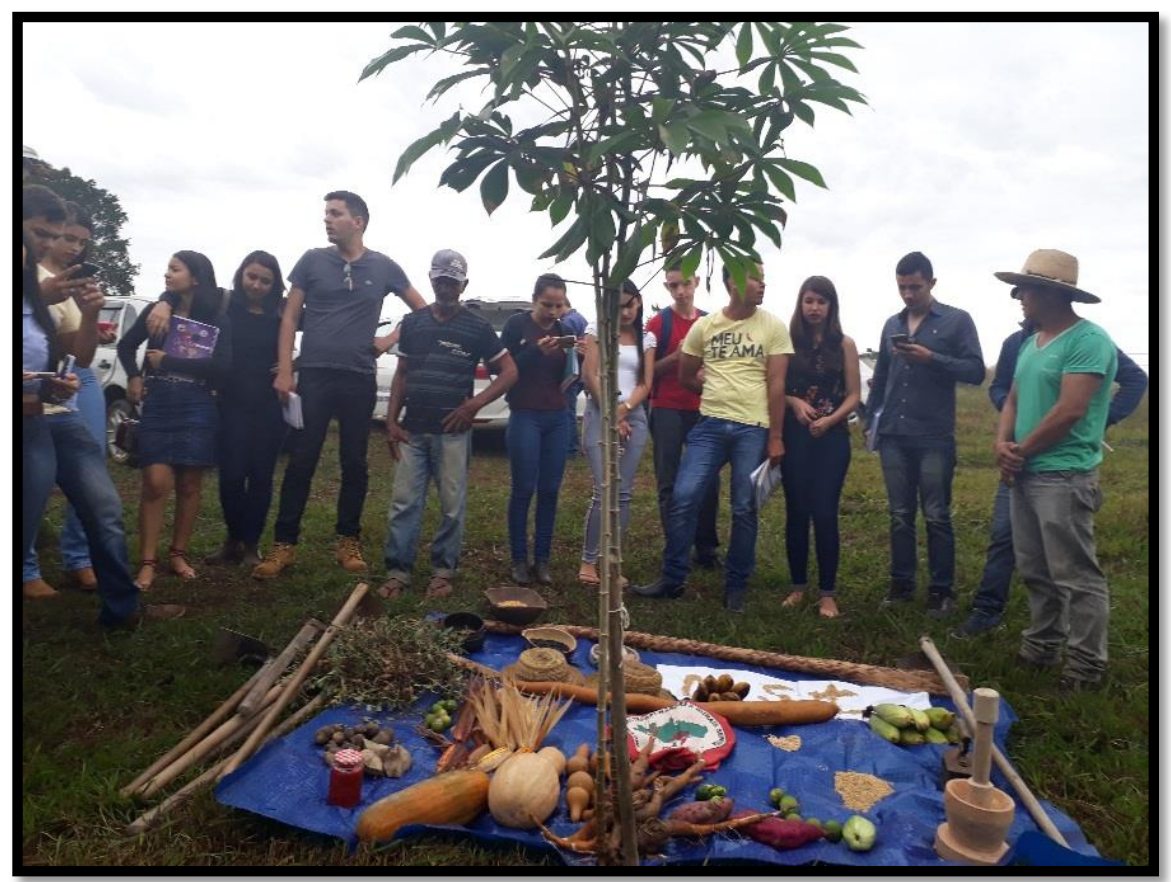

Figura 1 - Trabalho de campo no PA Paulo Gomes, 2018.

Fonte: arquivo próprio. 2018.

Após a mística e a rodada de apresentação, percorremos as áreas remanescentes de Cerrado até a lavoura comunitária de arroz. Houve então uma roda de conversa, na qual os assentados foram questionados sobre todo o ritual dos mutirões. Enquanto isso, a imaginação de um dos estudantes remontava à memória de suas próprias experiências:
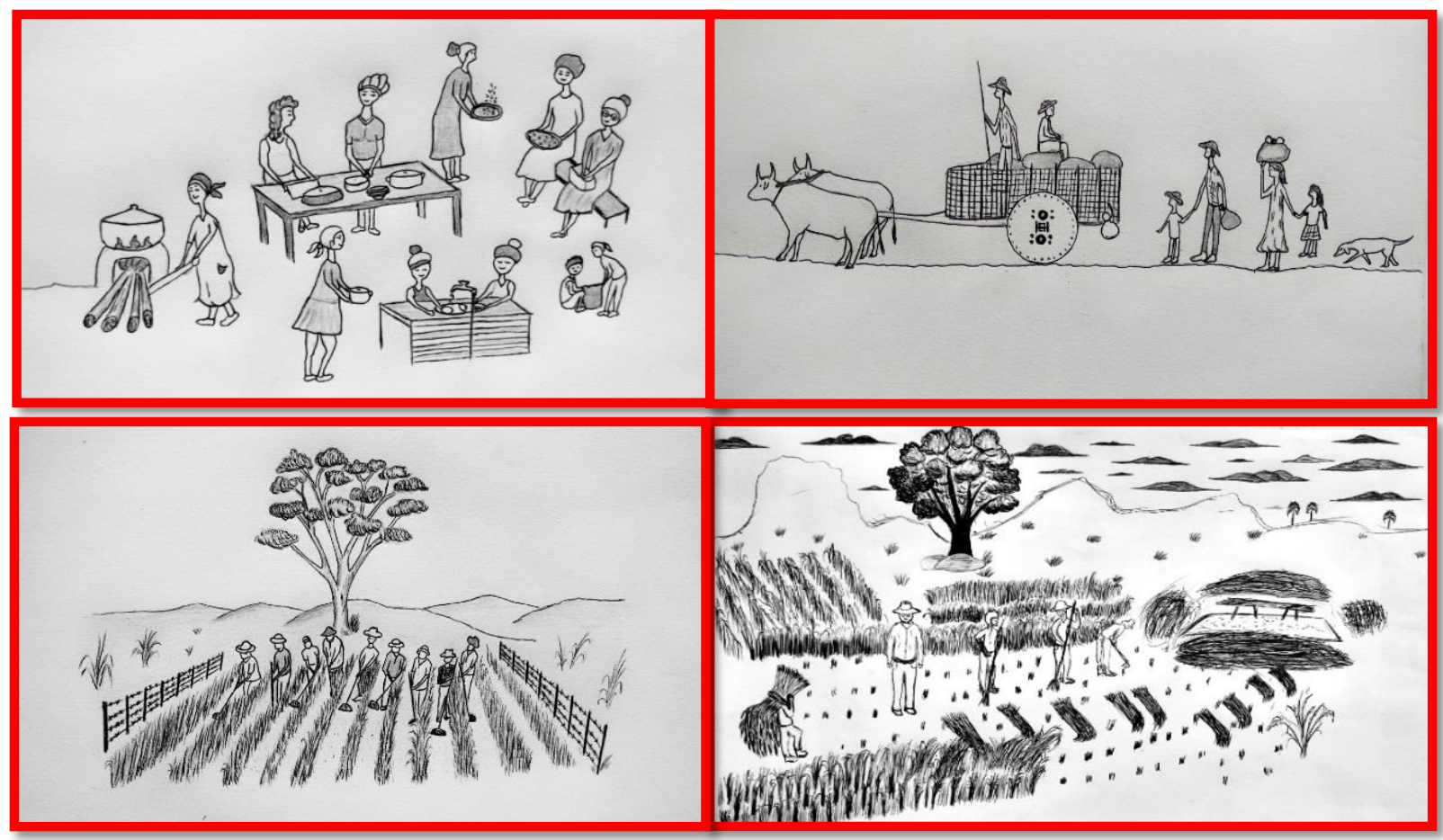

Figura 2 - 0 mutirão nos desenhos de Genildo F. da Costa, 2018.

Fonte: COSTA e MARQUES, 2018.

Estudos Geográficos, Rio Claro, 17(1): 205-215, jan./jun. 2019 (ISSN 1678-698X) http://www.periodicos.rc.biblioteca.unesp.br/index.php/estgeo 
Era a primeira vez que o artista criava desenhos para representar imagens espaciais extraídas de sua memória camponesa. Até então, havia apenas reproduzido desenhos em algumas experiências profissionais. Quando incitado a desenvolver seu trabalho de conclusão de curso sobre os desenhos enquanto formas de representação do espaço vivido, apresentou certa resistência.

"Eu nunca desenhei paisagens!"; "Eu tenho que representar aquilo que eu vi ou posso refazer algumas cenas a partir da minha memória?". O que ele queria saber era: posso expressar emoções nos desenhos? Isso seria aceito enquanto produto científico? Meus desenhos estão à altura de um TCC? Esquecera, entretanto, que desenhos são como mapas: "textos culturais, e não espelhos do mundo" (SEEMANN, 2012 p. 69).

As representações gráficas são "discursos sobre o território" (GIRARDI, 2005). No caso da obra do Genildo, ela se debruça sobre territórios ameaçados e negados nos mapas normativos, como os são os seus sujeitos e valores.

Após a produção dos desenhos, o estudante foi motivado a escrever sobre sua experiência de vida e trabalho no campo. Nas reuniões de orientação, os conteúdos de suas experiências eram debatidos e contrapostos a teorias e conceitos geográficos. Ao final, as narrativas de Genildo se mostraram potentes documentos das transformações no campo brasileiro e, junto aos seus desenhos, representam ricos materiais didáticos.

Seguem alguns trechos das narrativas autobiográficas extraídas do seu trabalho de conclusão de curso (inédito) defendido em dezembro de 2018, discriminados por temas:

\section{Quadro 1 - Narrativas autobiográficas - Genildo F. da Costa, 2018}

\begin{tabular}{|c|c|}
\hline $\begin{array}{c}\text { Família, moradia } \\
\text { e contratos de } \\
\text { trabalho }\end{array}$ & $\begin{array}{l}\text { Nasci no meio rural no fim da década de setenta, no município de } \\
\text { ltapuranga, em uma família composta por pai, mãe e cinco filhos, sendo } \\
\text { dois homens e três mulheres, dos quais sou um dos mais novos. A moradia } \\
\text { na área rural era em alguns casos como meeiro e em outras como } \\
\text { arrendatário. Nenhuma destas formas de trabalho eram remuneradas, ou } \\
\text { seja, o trabalhador não possuía nenhuma remuneração mensal e, nem tinha } \\
\text { seus direitos trabalhistas assegurados para si ou para seus filhos. } \\
\text { Eram contínuas as mudanças das famílias de produtores de uma } \\
\text { propriedade para outra, após o tempo de colheita ou de término de } \\
\text { produção de determinado produto. }\end{array}$ \\
\hline Infância & $\begin{array}{l}\text { A tuia [reservatório que se guardava o arroz colhido] era o meu lugar } \\
\text { preferido para brincadeiras de "putch" e esconde-esconde e de pular nas } \\
\text { pilhas de sacaria que serviam de escorregadores e trampolins. Havia a tuia } \\
\text { para a guarda de arroz para o uso cotidiano, que era um caixote em } \\
\text { tamanho mediano que servia para guardar o arroz com casca para o uso } \\
\text { cotidiano, era suspensa do chão e tinha tampa das mesmas madeiras das } \\
\text { quais ela havia sido feita. Após as colheitas do arroz ficavam as hastes do } \\
\text { arroz "palhada" que servia de amortecedor de quedas para as brincadeiras } \\
\text { de cambalhotas e para jogar bola. Após isto a palhada era batida (roçada) e } \\
\text { queimada para ficar como adubo natural para a terra melhorando o novo } \\
\text { plantio. }\end{array}$ \\
\hline $\begin{array}{l}\text { Meios de } \\
\text { produção }\end{array}$ & $\begin{array}{l}\text { O arroz era pilado (retirada da casca) no pilão ou na máquina, mas em geral } \\
\text { as máquinas eram na cidade e ficavam distantes, então se pilava o arroz no } \\
\text { pilão da casa. Nesse mesmo pilão eram feitas as paçocas de carne seca, } \\
\text { açafrão, amendoim para pé de moleque e paçoca, milho para canjica, café, } \\
\text { mamona para fazer azeite. } \\
\text { A plantação de milho era feita com cova de enxada ou enxadão por ser roça }\end{array}$ \\
\hline
\end{tabular}

Estudos Geográficos, Rio Claro, 17(1): 205-215, jan./jun. $2019 \quad$ (ISSN 1678—698X) http://www.periodicos.rc.biblioteca.unesp.br/index.php/estgeo 


\begin{tabular}{|c|c|}
\hline & $\begin{array}{l}\text { de toco. A adubação era feita com esterco de gado e às vezes com adubo } \\
\text { industrial. A capina das plantações era feita com enxada por causa dos } \\
\text { tocos que não permitiam a carpideira com trabalho animal. Quando era feito } \\
\text { em roça arada, por animal ou trator havia a possibilidade de utilização da } \\
\text { carpideira para a retirada dos matos, o que facilitava a limpeza das fileiras } \\
\text { do milho, melhorando a produtividade. }\end{array}$ \\
\hline $\begin{array}{l}\text { Precarização do } \\
\text { trabalho e a } \\
\text { migração } \\
\text { campo-cidade }\end{array}$ & $\begin{array}{l}\text { Tudo isto era feito em ciclos de produção entre a colheita e o novo plantio. } \\
\text { Nesse intervalo os trabalhadores procuravam outro tipo de trabalho para se } \\
\text { manterem até o início do outro plantio, que era denominado "empreitas" } \\
\text { onde se realizavam trabalhos de roçagens, aceiros, cercas, pontes etc. } \\
\text { Essa dependência do trabalho assalariado foi se intensificando ao longo do } \\
\text { tempo. } \\
\text { Esse tipo de trabalho temporário e esporádico era imprescindível para o } \\
\text { sustento da família no meio rural. Era um tipo de trabalho no qual se saía } \\
\text { de casa muito cedo, levando consigo uma marmita com comida } \\
\text { previamente feita no dia anterior ou no início da madrugada. Era muito raro } \\
\text { ter condições de lugar que pudesse aquecer essa comida, daí deriva o } \\
\text { nome de "boia-fria", função que exerci desde os doze anos, passando por } \\
\text { toda a adolescência até quando fui morar na cidade, já com vinte e cinco } \\
\text { anos. }\end{array}$ \\
\hline Educação & $\begin{array}{l}\text { A escola ficava a oito quilômetros de casa e não havia uniforme fornecido } \\
\text { pela escola e sim comprado pelos pais, mas o custo era altíssimo e isto } \\
\text { dificultava que as crianças estivessem uniformizadas. Esse percurso era } \\
\text { feito a pé por mim e pelos meus outros quatro irmãos e outros filhos de } \\
\text { agricultores que moravam nas proximidades ou em outras propriedades. } \\
\text { Eram oito quilômetros de ida e oito quilômetros de volta, e os objetos eram } \\
\text { transportados em "embornal", capangas, feitos pelas mães ou costureiras. } \\
\text { Em dias de chuvas, havia a solução de usar os sacos de açúcar para que } \\
\text { não molhassem os materiais de escola (caderno, borracha, lápis, cartilha). } \\
\text { As aulas eram das sete às onze e, depois do retorno da escola, as tarefas } \\
\text { de empreita já estavam com as ferramentas todas amoladas esperando } \\
\text { pelas nossas mãos para contribuírem. } \\
\text { Ao concluir o ensino fundamental na escola rural, não havia condições } \\
\text { financeiras de arcar com o deslocamento para a cidade para fazer o ensino } \\
\text { médio e a solução encontrada foi ir para a cidade junto com filhos de } \\
\text { outros agricultores, em caminhão 3/4, onde éramos transportados na } \\
\text { carroceria, fechado nas laterais e em cima com lona, com bancos de } \\
\text { madeira. Saindo das casas às cinco horas da manhã e retornando da } \\
\text { escola em torno de meio dia e meia. Para dar continuidade aos estudos, } \\
\text { realizei durante três anos os trabalhos de empreita, por dia e por tarefa } \\
\text { para ter condições de comprar livros e uniformes e manter os gastos com o } \\
\text { estudo. Desta maneira consegui concluir o ensino médio (2003), ficando } \\
\text { sem acesso à escolarização de nível superior até } 2015 \text {, quando ingressei } \\
\text { no curso de geografia da UEG Itapuranga. }\end{array}$ \\
\hline Mutirão & $\begin{array}{l}\text { Havia a permuta de dias de trabalhos entre trabalhadores rurais que eram } \\
\text { vizinhos. Havia também os mutirões ou "digitórios" para darem conta de } \\
\text { suas lidas diárias, ou seja, eram trabalhos cumpridos coletivamente entre } \\
\text { vizinhos e parceiros de outras comunidades e até mesmo gente que vinha } \\
\text { da cidade. Era um trabalho voluntariado. Quando o trabalhador tinha } \\
\text { condições de arcar com a alimentação dos dias de trabalho (café da } \\
\text { manhã, almoço, merenda e jantar) era denominado "mutirão", inclusive era } \\
\text { de responsabilidade do trabalhador todas as ferramentas e utensílios que } \\
\text { fossem necessários para cumprir a tarefa. No entanto, quando o } \\
\text { trabalhador não possuía condições de arcar com as alimentações e } \\
\text { mesmo com os utensílios para cumprirem a tarefa necessária, algum líder } \\
\text { local organizava a "TREIÇÃO" ou "TRAIÇÃO" sem que o trabalhador rural } \\
\text { soubesse que eles estavam se organizando para ajudar. }\end{array}$ \\
\hline $\begin{array}{c}\text { Festa e } \\
\text { compadrio }\end{array}$ & $\begin{array}{l}\text { A organização era feita durante a semana e se reuniam na sexta feira na } \\
\text { casa do líder, esperava passar da meia noite para chegarem na casa do }\end{array}$ \\
\hline
\end{tabular}

Estudos Geográficos, Rio Claro, 17(1): 205-215, jan./jun. 2019 (ISSN 1678-698X)




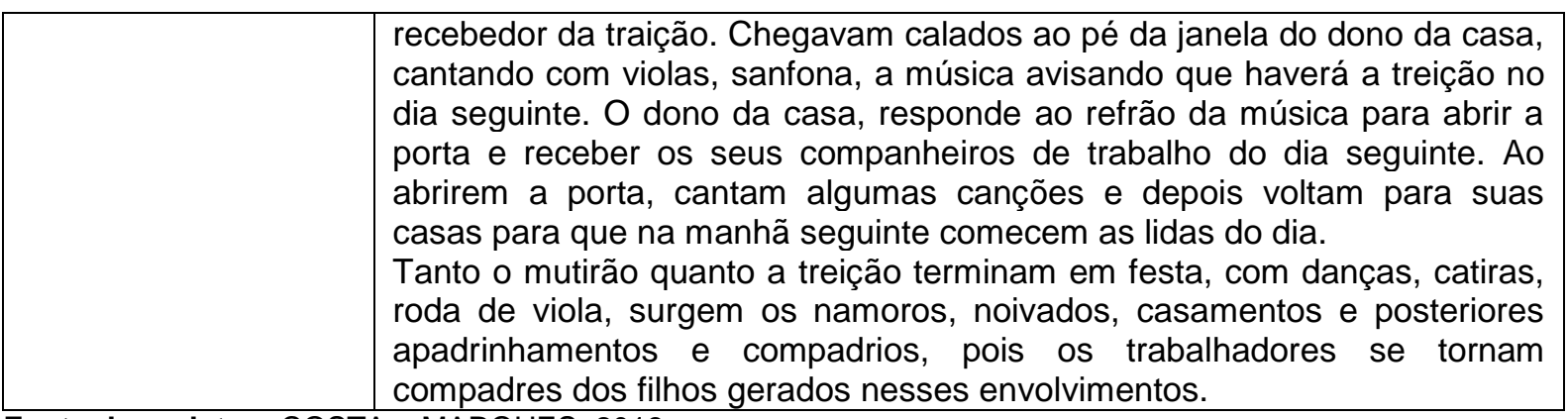

Fonte dos relatos: COSTA e MARQUES, 2018.

Organização: Marques, Ana C. O. de. 2019

As narrativas autobiográficas do estudante testemunham com riqueza de detalhes "geografias em forma-de-vida", expressão cunhada por Marandola Jr. (2018).

O encadeamento das experiências com os acontecimentos do espaço mais amplo - a mecanização da agricultura, a reestruturação produtiva da fazenda goiana, a obsolescência da figura do "agregado", o surgimento do boia-fria e o trabalho assalariado, a migração forçada campo-cidade tratada há muito na literatura como "êxodo rural", a concentração dos serviços sociais nas cidades, o sistema de crenças e valores do campesinato goiano - possibilita a reclamada compreensão multiescalar dos fenômenos, condição para o desenvolvimento do raciocínio geográfico.

Os desenhos e narrativas do estudante são tratados de Geografia Agrária. Além dos conteúdos, a linguagem certamente comunica com os estudantes da rede pública de ensino do município, à medida que estes também expressam traços da cultura camponesa. A pesquisa, neste caso, implicou avanços em duas direções: 1. A produção de material didático sensível ao contexto socioeconômico e cultural do município em questão; 2. Estimulou conexões entre as experiências do futuro professor e os conceitos e teorias geográficos, mobilizando assim, sua consciência espacial.

\section{CONSIDERAÇÕES FINAIS}

Licença para evocarmos um ditado popular: "ninguém dá o que não teve ou recebeu". Isso vale também para a relação entre o ensino e a formação de Professores. Beira a insensatez esperar que professores da rede básica desenvolvam o gosto pela pesquisa se esta não teve o devido peso em sua formação.

O mesmo raciocínio se aplica para a espera sensibilidade do professor à realidade em que atua. Como pode um professor de Geografia desenvolver uma prática docente sensível às particularidades dos sujeitos e lugares do ensinoaprendizagem sem saber o que os determina e que resistências insurgem? Se conhecer a realidade em que atua é condição para o exercício da docência, a pesquisa é parte integrante do ensino e precisa ser aprimorada nos cursos de formação de professores.

A experiência educativa e de pesquisa compartilhada neste artigo se mostrou alinhada às seguintes diretrizes da atuação docente:

1. Relacionar o conteúdo com a realidade cotidiana do estudante;

2. Exercitar a observação e a descrição a partir de recursos como a

Estudos Geográficos, Rio Claro, 17(1): 205-215, jan./jun. 2019 (ISSN 1678-698X) http://www.periodicos.rc.biblioteca.unesp.br/index.php/estgeo 
literatura, o cinema, a fotografia, o desenho;

3. Sobrepor variáveis (econômicas, demográficas, políticas, culturais) no estudo da realidade em questão e, sempre que possível, realizar estudos comparativos;

4. Incitar o desenvolvimento do raciocínio escalar e a imaginação espacial.

Esperamos - com a paciência camponesa - que o olhar encarnado de Genildo Francisco da Costa nas formas-de-vida que resistem em território do Cerrado desperte outras experiências educativas de formação do professorpesquisador.

\section{REFERÊNCIAS}

AMORIM FILHO, Oswaldo Bueno. A evolução do pensamento geográfico e a fenomenologia. Revista Sociedade \& Natureza, v. 11, n. 21/22, 1999. Disponível em: http://www.seer.ufu.br/index.php/sociedadenatureza. Acesso em: fev. 2019.

ARROYO, Miguel G. Currículo, território em disputa. Editora Vozes Limitada, 2014.

BERDOULAY, Vincent; ENTRIKIN, Nicholas. Lugar e sujeito: perspectivas teóricas. Qual o espaço do lugar, p. 93-116, 2012.

COSTA, Genildo. O Mutirão no Pré-Assentamento Paulo Gomes (ItapurangaGO): o desenho na representação de práticas espaciais (trabalho de conclusão de curso). Universidade Estadual de Goiás. Itapuranga, 2018.

FREIRE, Paulo. Pedagogia do oprimido. 17르. Ed. Rio de Janeiro: Paz e Terra, v. 3, p. 36, 1987.

FREITAS, Luiz Carlos de et al. Crítica da organização do trabalho pedagógico e da didática. 1994.

GIRARDI, Gisele. Aventuras da leitura de mapas. A aventura cartográfica: perspectivas, pesquisas e reflexões sobre a cartografia humana. Fortaleza: Expressão Gráfica e Editora, p. 61-72, 2005.

GIROTTO, Eduardo Donizeti. Ensino de Geografia e Raciocínio Geográfico: as contribuições de Pistrak para a superação da dicotomia curricular. Revista Brasileira de Educação em Geografia, v. 5, n. 9, p. 71-86, 2015. Disponível em: http://www.revistaedugeo.com.br. Acesso em: abr. 2019.

KOZEL, Salete; FILIZOLA, Roberto. Didática de Geografia: memórias da terra: o espaço vivido. São Paulo: FTD, 1996.

Estudos Geográficos, Rio Claro, 17(1): 205-215, jan./jun. 2019 (ISSN 1678-698X) http://www.periodicos.rc.biblioteca.unesp.br/index.php/estgeo 
LACOSTE, Yves. A geografia-isso serve, em primeiro lugar, para fazer a guerra. Papirus, 2005.

MARANDOLA JR., Eduardo. Olhar encarnado, geografias em formas-de-vida. GeoTextos, vol. 14, n. 2, dezembro 2018. E. Marandola Jr. 237-254. Disponível em: https://portalseer.ufba. br/index.php/geotextos/article/view/28599/0. Acesso em Abr. 2019.

SANTOS, Douglas. O que é Geografia. São Paulo, 2007.

SEEMANN, Jorn. Tradições Humanistas na Cartografia e a Poética dos mapas. Qual o espaço do lugar, p. 69-92, 2012.

SUERTEGARAY, Dirce Maria Antunes. Pesquisa de campo em geografia. GEOgraphia, $\quad$ v. $4, \quad$ n. $7, \quad$ p. 64-68, 2002. Disponível em: http://periodicos.uff.br/geographia/article/view/13423. Acesso em Jun. 2019. 